\title{
ARTICLE
}

\section{Measurement of Beam Data for Small Radiosurgical Fields: Comparison of CyberKnife Multi-sites in Korea}

\author{
Jisun JANG ${ }^{1,6}$, Young-Nam KANG ${ }^{2 *}$, Hun-Joo SHIN ${ }^{3,6}$, Jae-Hyuk SEO ${ }^{3,6}$, Moon-Chan KIM ${ }^{1,4}$, \\ Dong-Joon LEE ${ }^{5}$, and Soo-Il KWON ${ }^{6}$ \\ ${ }^{I}$ CyberKnife Center, Seoul St.Mary's Hospital, The Catholic University of Korea, \#505 Banpo-Dong, Seocho-Gu,Seoul,137-701,Korea \\ ${ }^{2}$ Department of Radiation Oncology, Seoul St.Mary's Hospital, The Catholic University of Korea, Seoul, Korea \\ ${ }^{3}$ CyberKnife Clinic, Wooridul Spine Hospital, Seoul, Korea \\ ${ }^{4}$ Department of Neurosurgery, Seoul St.Mary's Hospital, The Catholic University of Korea, Seoul, Korea \\ ${ }^{5}$ Department of Neurosurgery, Ilsan Paik Hospital, College of Medicine, Inje University, Ilsan, Korea \\ ${ }^{6}$ Department of Medical Physics, Graduate School of Kyonggi University, Suwon, Korea
}

\begin{abstract}
The diode detector is recommended to measure the beam from CyberKnife recently. In this study, various detectors had been used to measure the beam data and compared that for each CyberKnife of domestic and foreign departments. All measurements of the beam data were performed by several detectors: diode detector, ion chamber, Gafchromic EBT film. These measured data compared with CyberKnife sites of the Korea. Also, these measured data are compared to a set of nationwide average data.

For the collimators over than $20 \mathrm{~mm}$, the beam data (TPR and OCR) from the different detectors showed a good agreement within $\pm 3 \%$. For the collimators less than $20 \mathrm{~mm}$, the beam data have discrepancy of $10 \%$ or more for each detector. Comparing the measured output factors in this study and the average of foreign departments provided by Accuary, the agreement was less than $\pm 0.5 \%$ except for $5 \mathrm{~mm}$ collimators for diode detector and $\pm 1.5 \%$ for Gafchromic EBT film. For the collimators over than $20 \mathrm{~mm}$, the beam data from the multi-sites showed a good agreement within $\pm 1 \%$. For the collimators less than $20 \mathrm{~mm}$, it was found that the effective volume and the material of the detector affect the beam data.
\end{abstract}

KEYWORDS: CyberKnife, small field dosimetry, stereotactic radiosurgery

\section{Introduction}

The use of stereotactic radiosurgical systems to treat intracranial and extracranial tumors and other lesions requires a high degree of accuracy in target identification and localization. The CyberKnife radiosurgery system can deliver, with a high degree of precision, a single or several fractions of radiation dose to a well-defined small intracranial or extracranial target. ${ }^{1-3)}$

The accuracy of the beam data directly affects the accuracy of dose delivery in CyberKnife system. This is of obvious importance for any SRS system, particularly when a single large radiation dose is delivered to a small selected target with the $5 \mathrm{~mm}$ collimator, as in treatment of trigeminal neuralgia. Accurate dosimetry of small-field photon beams used in stereotactic radiosurgery can be made difficult because of the presence of lateral electronic disequilibrium and steep dose gradients. In the published literature, data acquisition for radiosurgery is mainly based on diode and film dosimetry, small sensitive volume ionization chamber and thermolominescence dosimetry (TLD). ${ }^{3-6)}$

The CyberKnife system has generally been performed using a p-type silicon diode detector with a very small active volume. The diode detector is recommended to measure the beam from CyberKnife system recently. In this study, various detectors had been used to measure the beam data

*Corresponding Author, E-mail:k3yn@catholic.ac.kr

(C) Atomic Energy Society of Japan and compared that for each CyberKnife of domestic and foreign departments.

\section{Materials and Methods}

The CyberKnife (Accuray, Sunnyvale, CA, USA) system consists of a $6 \mathrm{MV}$ linear accelerator mounted on a robotic arm. For the collimation of CyberKnife, 12 circular cones are available, collimators of different sizes, including 5, 7.5, $10,12.5,15,20,25,30,35,40,50$, and $60 \mathrm{~mm}^{1-3)}$

The tissue phantom ratio (TPR) and off center ratio (OCR) measurements were carried out using the detectors positioned in the computer controlled water phantom.

Measurements of the TPR and OCR for all 12 collimators were performed by two detectors: diode detector, $0.125 \mathrm{cc}$ ion chamber. The reference depth used for normalization of the TPR data was $1.5 \mathrm{~cm}$ for all collimator sizes, which is the nominal depth of maximum dose. All measurements were made at a $\mathrm{SAD}$ of $80 \mathrm{~cm}$.

The OCR at a particular depth is the ratio of the absorbed dose at a given off-axis point relative to the dose at central axis. Measurements of OCR were carried out by conducting orthogonal scans across the field at a variety of depths. OCR measurements were made for depths ranging from $1.5 \mathrm{~cm}$ to $30 \mathrm{~cm}$ and off-axis distance ranging from $0 \mathrm{~cm}$ to $6.0 \mathrm{~cm}$.

Measurements of the output factors for all 12 collimators were performed by three detectors: diode detector, $0.015 \mathrm{cc}$ ion chamber, Gafchromic EBT film. The diode detector is a p-type silicon diode for the measurement of dose 
distributions of high energy photons in radiation therapy. A typical effective thickness of the measuring volume for this detector is $2.5 \mu \mathrm{m}$. The diode detector and ion chamber measurement were performed with water phantom. The diode detector and ion chamber were set at $1.5 \mathrm{~cm}$ depth with a SAD $80 \mathrm{~cm}$. In the Gafchromic EBT film measurement, the water phantom was replaced with a solidwater phantom. The films were irradiated with a dose of 200 MU. The exposed films were scanned using an Epson Expression 1680 scanner and analyzed using VeriSoft software. Each collimator normalized with respects to the output factor of the largest collimator $(60 \mathrm{~mm})$ at $80 \mathrm{~cm}$ $\mathrm{SAD}$ and $1.5 \mathrm{~cm}$ depth.

These measured data were compared to a set of standard average data, which provided by Accuray. The standard average data are an average of the measurements made by CyberKnife sites.

\section{Results}

\section{TPR and OCR}

We obtained the beam data (TPR and OCR) of 12 sizes of collimators using the two different detectors (diode detector, 0.125 cc ion chamber).

Figure 1 shows the TPR curves for $6 \mathrm{MV}$ beams at a 5, $7.5,12.5$, and $20 \mathrm{~mm}$ field size measured with the diode detector in comparison with ion chamber. For the collimators over than $20 \mathrm{~mm}$, the beam data (TPR and OCR) from the different detectors showed a good agreement within $\pm 3 \%$.
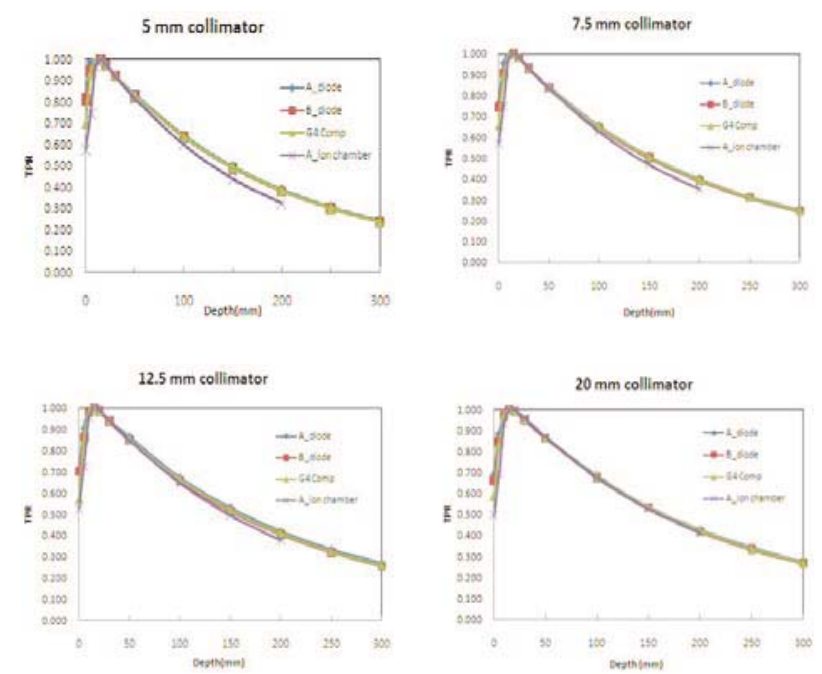

Fig. 1 TPR measured using the diode detector (A, B hospital and G4 system standard average data) and ion chamber (A hospital) for fields of 5, 7.5, 12.5, and $20 \mathrm{~mm}$.

However, it is easily observed that the ion chamber was broadens the measured penumbra width in the OCR data. The broadening effect is more enhanced with decreasing beam diameter. For the collimators less than $20 \mathrm{~mm}$, the beam data have discrepancy of $10 \%$ or more for each detector (Fig. 2).

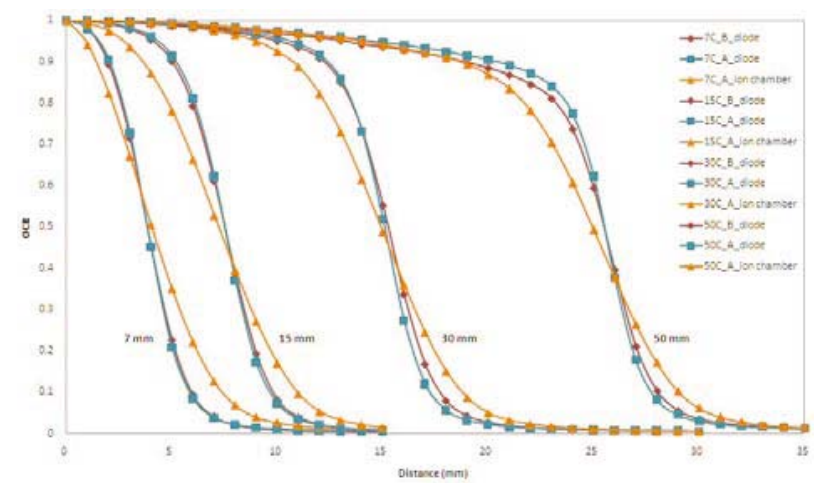

Fig. 2 The OCR measured with diode detector (A hospital) are compared to those measured with ion chamber (A hospital) and diode detector (B hospital) for collimator diameters. The profiles are for a $7 \mathrm{~mm}, 15 \mathrm{~mm}, 30 \mathrm{~mm}$, and $50 \mathrm{~mm}$ collimator, respectively. All profiles are taken at $1.5 \mathrm{~cm}$ depth water at $80 \mathrm{~cm} \mathrm{SAD.}$

The measured TPR and OCR using diode detector were found to be in good agreement with multi-site data which provided by Accuray. The greatest discrepancy between the measured data and the average data occurred for the surface measurement of the TPR.

\section{Output Factor}

We obtained the output factors of 12 sizes of collimators using the three different detectors (diode detector, $0.015 \mathrm{cc}$ ion chamber, Gafchromic EBT film) (Table 1).

Table 1 Summary of output factors measured with different detectors

\begin{tabular}{cccc}
\hline \hline $\begin{array}{c}\text { Collimator } \\
\text { Size }(\mathrm{mm})\end{array}$ & $\begin{array}{c}0.015 \mathrm{cc} \\
\text { Ion Chamber }\end{array}$ & $\begin{array}{c}\text { Diode } \\
\text { Detector }\end{array}$ & $\begin{array}{c}\text { Gafchromic } \\
\text { EBT Film }\end{array}$ \\
\hline 5 & 0.635 & 0.685 & 0.734 \\
7.5 & 0.772 & 0.867 & 0.876 \\
10 & 0.850 & 0.912 & 0.923 \\
12.5 & 0.905 & 0.945 & 0.952 \\
15 & 0.936 & 0.962 & 0.967 \\
20 & 0.966 & 0.978 & 0.968 \\
25 & 0.977 & 0.985 & 0.968 \\
30 & 0.984 & 0.988 & 0.981 \\
35 & 0.987 & 0.991 & 0.990 \\
40 & 0.991 & 0.993 & 0.990 \\
50 & 0.996 & 0.997 & 0.994 \\
60 & 1.000 & 1.000 & 1.000 \\
\hline \hline
\end{tabular}

Figure 3 shows output factors measured as a function of the collimator size of $5 \sim 60 \mathrm{~mm}$ from the CyberKnife using three detectors. For the collimators over than $20 \mathrm{~mm}$, the output factors from the different detectors showed a good agreement within $\pm 1 \%$. However, for the collimators less than $20 \mathrm{~mm}$, the output factors have discrepancy of $10 \%$ or more for each detector. 


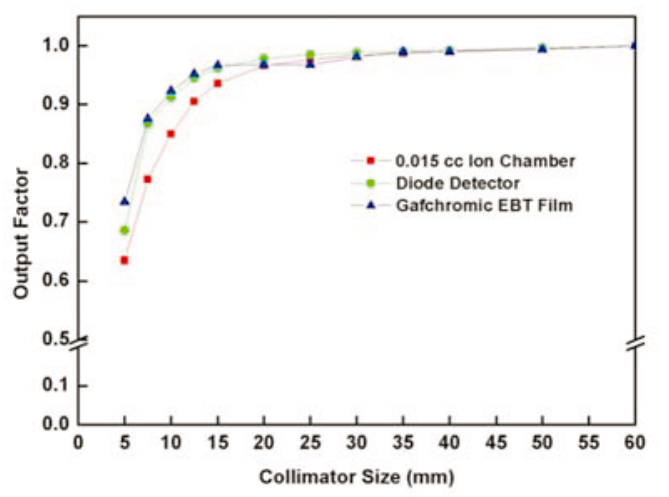

Fig. 3 Comparison of output factors measured with the diode detector, ion chamber and Gafchromic EBT film for collimator size of $5 \sim 60 \mathrm{~mm}$. The measured output factors are normalized to a $60 \mathrm{~mm}$ collimator.

Comparing the measured output factors in this study and the average of foreign departments provided by Accuary, the agreement was less than $\pm 0.5 \%$ except for $5 \mathrm{~mm}$ collimators for diode detector and $\pm 1.5 \%$ for Gafchromic EBT film. The discrepancy of output factor for $5 \mathrm{~mm}$ collimators measured with both Gafchromic EBT film and diode detector were $3.5 \%$ (Table 2).

The output factors measured with diode detector of the domestic sites (A $\sim \mathrm{D}$ hospital) were found to be in good agreement with multi-site data which provided by Accuray except for $5 \mathrm{~mm}$ collimator (Table 3).

Table 2 Percentage disagreement between measured output factors and standard output factors

\begin{tabular}{ccccc}
\hline \hline $\begin{array}{c}\text { Collimator } \\
\text { Size (mm) }\end{array}$ & $\begin{array}{c}\text { Accuray Ave. } \\
\text { (diode) }\end{array}$ & $\begin{array}{c}0.015 \mathrm{cc} \\
\text { \% Difference }\end{array}$ & $\begin{array}{c}\text { Diode } \\
\text { \% Difference }\end{array}$ & $\begin{array}{c}\text { Gaf-EBT film } \\
\text { \% Difference }\end{array}$ \\
\hline 5 & 0.710 & -10.56 & -3.52 & 3.38 \\
7.5 & 0.869 & -11.16 & -0.23 & 0.81 \\
10 & 0.912 & -6.80 & 0.00 & 1.21 \\
12.5 & 0.942 & -3.93 & 0.32 & 1.06 \\
15 & 0.959 & -2.40 & 0.31 & 0.83 \\
20 & 0.975 & -0.92 & 0.31 & -0.72 \\
25 & 0.982 & -0.51 & 0.31 & -1.43 \\
30 & 0.986 & -0.20 & 0.20 & -0.51 \\
35 & 0.989 & -0.20 & 0.20 & 0.10 \\
40 & 0.992 & -0.10 & 0.10 & -0.20 \\
50 & 0.994 & 0.20 & 0.30 & 0.00 \\
60 & 1.000 & 0.00 & 0.00 & 0.00 \\
\hline \hline
\end{tabular}

Table 4 shows the output factors for the $5 \sim 60 \mathrm{~mm}$ collimator size as determined by previous investigators using various diode detectors, Gafchromic EBT film and Monte-Carlo calculation. ${ }^{5,7-9)}$

For the collimators over than $20 \mathrm{~mm}$, the beam data from the multi-sites showed a good agreement within $\pm 1 \%$. For the collimators less than $20 \mathrm{~mm}$, it was found that the effective volume and the material of the detector affect the beam data (Table 5).
Table 3 Percentage disagreement between output factors of the domestic sites and standard output factors

\begin{tabular}{cccccc}
\hline \hline $\begin{array}{c}\text { Collimator } \\
\text { Size }(\mathrm{mm})\end{array}$ & $\begin{array}{c}\mathrm{A} \\
\text { Hospital }^{*}\end{array}$ & $\begin{array}{c}\mathrm{B} \\
\text { Hospital }^{*}\end{array}$ & $\begin{array}{c}\mathrm{C} \\
\text { Hospital }^{*}\end{array}$ & $\begin{array}{c}\mathrm{D} \\
\text { Hospital }^{*}\end{array}$ & $\begin{array}{c}\mathrm{E} \\
\text { Hospital }^{* *}\end{array}$ \\
\hline 5 & -3.52 & -0.27 & 0.14 & 0.28 & -13.38 \\
7.5 & -0.23 & 0.23 & -0.35 & 0.23 & -9.32 \\
10 & 0.00 & 0.00 & -0.55 & -0.55 & -6.47 \\
12.5 & 0.32 & 0.00 & -0.32 & 0.32 & -4.56 \\
15 & 0.31 & 0.00 & -0.31 & 0.10 & -3.23 \\
20 & 0.31 & -0.10 & -0.31 & 0.00 & -1.54 \\
25 & 0.31 & -0.10 & -0.20 & -0.10 & -0.81 \\
30 & 0.20 & -0.10 & -0.10 & -0.10 & -0.61 \\
35 & 0.20 & -0.10 & 0.00 & 0.00 & -0.30 \\
40 & 0.10 & -0.10 & -0.10 & 0.00 & -0.30 \\
50 & 0.30 & 0.20 & 0.30 & 0.40 & 0.20 \\
60 & 0.00 & 0.00 & 0.00 & 0.00 & 0.00 \\
\hline \hline
\end{tabular}

Table 4 Comparison of the output factors of the foreign sites

\begin{tabular}{ccccccc}
\hline $\begin{array}{c}\text { Collimator } \\
\text { Size }(\mathrm{mm})\end{array}$ & $\begin{array}{c}\text { Accuray } \\
\text { Ave. } \\
\text { (PTW } \\
\text { diode) }\end{array}$ & $\begin{array}{c}\text { Yale } \\
\text { Univ. } \\
\text { (MC } \\
\text { data) }\end{array}$ & $\begin{array}{c}\text { Keck } \\
\text { School of } \\
\text { Medicine } \\
\text { (Scandit } \\
\text { ronix } \\
\text { diode) }\end{array}$ & $\begin{array}{c}\text { Parkview } \\
\text { Compre- } \\
\text {-hensive } \\
\text { Cancer } \\
\text { Center } \\
\text { (PTW } \\
\text { diode) }\end{array}$ & $\begin{array}{c}\text { Saint } \\
\text { Francis } \\
\text { Hosp. } \\
\text { (PTW } \\
\text { diode) }\end{array}$ & $\begin{array}{c}\text { Saint } \\
\text { Francis } \\
\text { Hosp. } \\
\text { (Gilm) } \\
\text { film }\end{array}$ \\
\hline 5 & 0.710 & 0.611 & 0.719 & 0.704 & 0.709 & 0.701 \\
7.5 & 0.869 & 0.847 & 0.849 & 0.877 & 0.869 & 0.845 \\
10 & 0.912 & 0.881 & 0.892 & 0.916 & 0.911 & 0.902 \\
12.5 & 0.942 & 0.925 & 0.926 & 0.946 & 0.941 & 0.934 \\
15 & 0.959 & 0.948 & 0.947 & 0.961 & 0.958 & 0.959 \\
20 & 0.975 & 0.972 & 0.967 & 0.976 & 0.974 & 0.980 \\
25 & 0.982 & 0.980 & 0.977 & 0.983 & 0.981 & 0.987 \\
30 & 0.986 & 0.987 & 0.984 & 0.986 & 0.986 & 0.993 \\
35 & 0.989 & 0.990 & 0.987 & 0.990 & 0.990 & 0.993 \\
40 & 0.992 & 0.994 & 0.990 & 0.992 & 0.993 & 0.997 \\
50 & 0.994 & 0.998 & 0.996 & 0.996 & 0.997 & 0.997 \\
60 & 1.000 & 1.000 & 1.000 & 1.000 & 1.000 & 1.000 \\
\hline \hline
\end{tabular}

Table 5 Percentage disagreement between output factors of the foreign sites and standard output factors

\begin{tabular}{|c|c|c|c|c|c|c|}
\hline $\begin{array}{l}\text { Collimator } \\
\text { Size }(\mathrm{mm})\end{array}$ & $\begin{array}{l}\text { In This } \\
\text { Study } \\
\text { (PTW } \\
\text { diode) }\end{array}$ & $\begin{array}{l}\text { Yale } \\
\text { Univ. } \\
\text { (MC } \\
\text { data) }\end{array}$ & $\begin{array}{l}\text { Keck } \\
\text { School of } \\
\text { Medicine } \\
\text { (Scandit } \\
\text {-ronix } \\
\text { diode) }\end{array}$ & 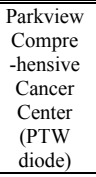 & $\begin{array}{c}\text { Saint } \\
\text { Francis } \\
\text { Hosp. } \\
\text { (PTW } \\
\text { diode) }\end{array}$ & $\begin{array}{c}\text { Saint } \\
\text { Francis } \\
\text { Hosp. } \\
\text { (Gaf EBT } \\
\text { film) }\end{array}$ \\
\hline 5 & -3.52 & -13.94 & 1.27 & -0.85 & -0.14 & -1.27 \\
\hline 7.5 & -0.23 & -2.53 & -2.30 & 0.92 & 0.00 & -2.76 \\
\hline 10 & 0.00 & -3.40 & -2.19 & 0.44 & -0.11 & -1.10 \\
\hline 12.5 & 0.32 & -1.80 & -1.70 & 0.42 & -0.11 & -0.85 \\
\hline 15 & 0.31 & -1.15 & -1.25 & 0.21 & -0.10 & 0.00 \\
\hline 20 & 0.31 & -0.31 & -0.82 & 0.10 & -0.10 & 0.51 \\
\hline 25 & 0.31 & -0.20 & -0.51 & 0.10 & -0.10 & 0.51 \\
\hline 30 & 0.20 & 0.10 & -0.20 & 0.00 & 0.00 & 0.71 \\
\hline 35 & 0.20 & 0.10 & -0.20 & 0.10 & 0.10 & 0.40 \\
\hline 40 & 0.10 & 0.20 & -0.20 & 0.00 & 0.10 & 0.50 \\
\hline 50 & 0.30 & 0.40 & 0.20 & 0.20 & 0.30 & 0.30 \\
\hline
\end{tabular}

\section{Conclusion}

We evaluated the use of the detectors for beam data measurements in the CyberKnife collimators. Accurate measurements of beam data for radiosurgical beams are an essential prerequisite for the treatment of trigeminal 
neuralgia, which uses a $5 \mathrm{~mm}$ collimator. However, beam data measurements of stereotactic radiation fields are difficult because lateral electronic disequilibrium and steep dose gradients exist in large portions of these fields. The ideal dosimeter needs to have good spatial resolution and have linear and reproducible response.

In this study, a small sensitive volume ion chamber was found to significantly overestimate the penumbra of small fields, with the relative amount of overestimation being more severe as the field size decreases. Although the ionization chamber has a small volume of $0.015 \mathrm{cc}$, the pinpoint chamber is still too large to accurately measure the beam data of collimators less than $20 \mathrm{~mm}$ in diameter.

The measured TPR, OCR and output factors were found to be in good agreement with average multi-site data except for $5 \mathrm{~mm}$ collimator. For the collimators over than $20 \mathrm{~mm}$, the beam data from the multi-sites showed a good agreement within $\pm 1 \%$. For the collimators less than $20 \mathrm{~mm}$, it was found that the effective volume and the material of the detector affect the beam data.

\section{References}

1) J.R. Adler, M.J. Murphy, S.D. Chang et al., "Image-guided robotic radiosurgery," Neurosurgery, 44, 1299 (1999)
2) J.S. Kuo, C. Yu, Z. Petrovich, et al., "The CyberKnife stereotactic radiosurgery system: description, installation, and an initial evaluation of use and functionality," Neurosurgery, 52, 1235 (2003)

3) J.S. Jang, Y.N. Kang, D.O. Shin, et al., "Analysis of relativeoutput factors for CyberKnife: comparison of ion chambers, diode detector and films," Korea J. Med. Phys., $17[1], 47(2006)$

4) O.A. Sauer, J. Wilbert, "Measurement of output factors for small photon beams," Med. Phys., 34[6], 1983 (2007)

5) E.E. Wilcox, G.M. Daskalov, "Evaluation of GAFCHROMIC $^{\circledR}$ EBT film for CyberKnife ${ }^{\circledR}$ dosimetry," Med. Phys., 34[6], 1967 (2007)

6) I. Griessbach, M. Lapp, J. Bohsung, et al., "Dosimetric characteristics of a new unshielded silicon diode and its application in clinical photon and electron beams," Med. Phys., 32[12], 3750 (2005)

7) C. Yu, G. Jozsef, M. L.J. Apuzzo, et al., "Measurements of the relative output factors for CyberKnife collimators," Neurosurgery, 54[1], 157 (2004)

8) S.C.Sharma, J.T. Ott, J.B. Williams, et al., "Commissioning and acceptance testing of a CyberKnife linear accelerator," J. Appl. Clin. Med. Phys., 8[3], 119 (2007)

9) J. Deng, T. Guerrero, C.M. Ma, R. Nath, "Modelling 6 MV photon beams of a stereotactic radiosurgery system for Monte Carlo treatment planning,” Phys. Med. Biol., 49, 1689 (2004) 